\title{
Surgery without incisions; experiences in single incision laparoscopic surgery (SILS) for infants and children
}

\begin{abstract}
Single-incision laparoscopic surgery is minimal access surgery with only one small incision result in very small scar after the surgery almost like scarless surgery. In this article, the authors present and discuss the potential benefits of surgical technique the single incision laparoscopic surgery (SILS), why as pediatric surgeons now days need to cope with, and what are the surgeries that can be manages by SILS As a single surgeon the author present 68 patients who underwent single incision laparoscopic surgery for appendicitis, inguinal hernia, diagnostic laparoscopic surgery, lymph nodes and bowel biopsies, and cholecystectomy from November 2015 to May 2017. The evidence for the large benefits to the patient will be presented, as well as the considerable. The single incision laparoscopic surgery (SILS) approach offer advantages others than fine cosmetic result as no incisions, children comforts, less surgical stress? decreased of infection, in addition there is less postoperative analgesia, shortens postoperative overall hospital stay and better clinical information.
\end{abstract}

Volume 7 Issue 6 - 2017

\section{R Bilommi \\ Department of Pediatric Surgery, Mitra Keluarga Group General Hospital, Indonesia}

Correspondence: R Bilommi, Department of Pediatric Surgery, Mitra Keluarga Group General Hospital,YARSI Medical Faculty, Indonesia, Email rbilommi@gmail.com

Received: December 01, 2017| Published: December 19, 2017

Keywords: paediatric, single incision of laparoscopic surgery, SILS

\section{Introduction}

Single-incision laparoscopic surgery is a very exciting new modality in the field of minimal access surgery which works for further reducing the scars of standard laparoscopy and towards scar less surgery. ${ }^{1-3}$ Scar less surgery is the Holy Grail of surgery. ${ }^{4}$ In the old days adults laparoscopic surgery somehow has more fame around the globe, many cases or journals has been widely published before. Now days pediatric surgeon worldwide has done many surgical procedures for congenital anomalies. Paediatric laparoscopy has been first described in 1923 by Kelling, Minimal Access Surgery was the reduction of scars and thereby pain and suffering of the patients. Over the last two decades, conventional multi-port Minimal Access Surgery (MAS) has established itself as the gold standard for almost all abdominal surgical procedures. The procedure provides safety. ${ }^{1,46}$ Laparoscopy in neonates has evolved even more slowly when compared to other age groups. Extremely small size of the abdominal cavity causes increased risk of visceral injury and technical difficulty of maneuvering oversized instruments. ${ }^{4-8}$ (Figure 1) (Figure 2).

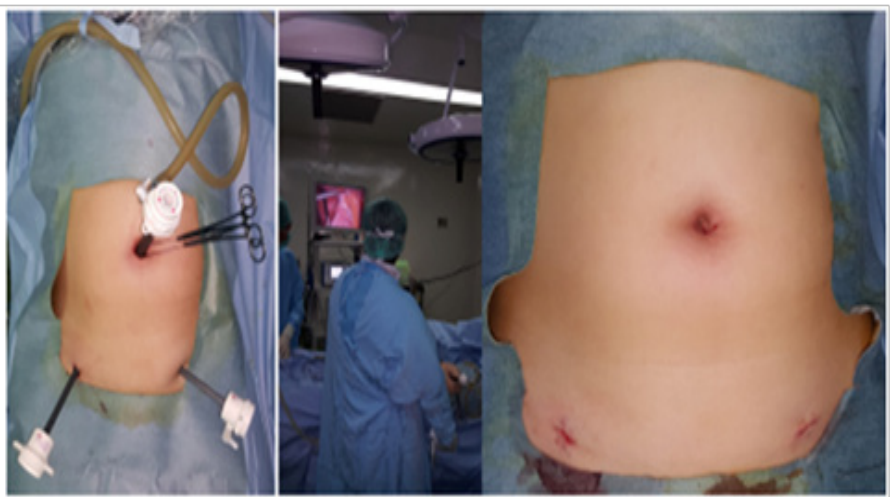

Figure I Conventional Laparoscopic Surgery.

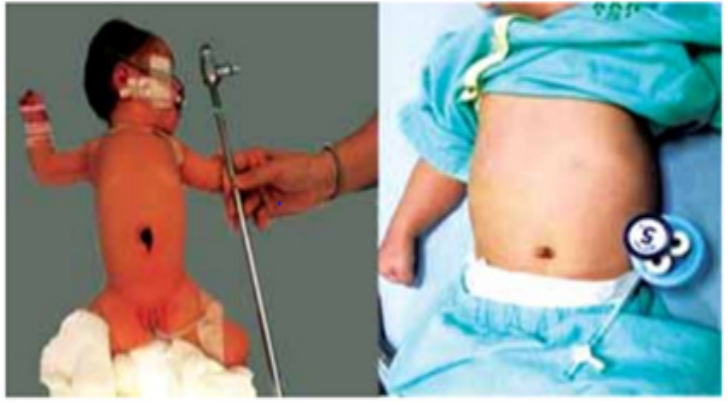

Figure 2 A comparison of instrument (left-laparoscope, right-SILS PORT) and patient size.

\section{Methods}

As a single surgeon the author present 68 patients who underwent single incision laparoscopic surgery for appendicitis, inguinal hernia, diagnostic laparoscopic surgery, lymph nodes and bowel biopsies, and cholecystectomy from November 2015 to May 2017. Data were collected on patient age, sex, date of admission, date of surgery, date of discharge, surgical complications, operative time, and hospital costs for the procedure, costs of the overall hospital visit, post operative result in pediatric surgery clinic 2 weeks after surgery.

\section{Results}

67 patients underwent SILS, The average age of the patients was 8years (range 6Months-14Years old). Indications for the operation were appendectomy in 43 patients, 7 for inguinal hernia, 7 patients for diagnostic laparoscopic, 5 patients for intra bowel or lymph nodes biopsies and 2 for cholecystectomy, 3 for orchidopexy.

None of the SILS surgeries required conversion to a traditional technique, nor did any patient require conversion to an open technique. No surgical complications in any patients, operative time $20 \%$ longer 
than the open procedure. Less hospital costs for the procedure, costs of the overall hospital visit, and post operative result in pediatric surgery clinic 2 weeks after surgery satisfying in all patients including the cosmetic as pec because of the very small skin's scar (Table 1).

Table I cosmetic aspect because of the very small skin's scar

\begin{tabular}{|c|c|c|c|c|c|c|}
\hline & $\begin{array}{l}\text { Number of } \\
\text { patients }\end{array}$ & $\begin{array}{l}\text { Convert to } \\
\text { open surgery }\end{array}$ & $\begin{array}{l}\text { Post operation } \\
\text { pain scales }\end{array}$ & $\begin{array}{l}\text { Post operation } \\
\text { hospital Stay }\end{array}$ & Complication & $\begin{array}{l}\text { Cosmetic } \\
\text { result }\end{array}$ \\
\hline Appendectomy & 43 & 2 & 2-Jan & $\begin{array}{l}\text { Less than open } \\
\text { surgery }\end{array}$ & --- & $\begin{array}{l}2 \text { keloids } \\
\text { performed }\end{array}$ \\
\hline Herniotomy & 7 & 0 & $0-1$ & $\begin{array}{l}\text { Less than open } \\
\text { surgery }\end{array}$ & --- & $\begin{array}{l}\text { I keloids } \\
\text { performed }\end{array}$ \\
\hline $\begin{array}{l}\text { Bowel or lymphs } \\
\text { nodes }\end{array}$ & 5 & 0 & $0-1$ & $\begin{array}{l}\text { Less than open } \\
\text { surgery }\end{array}$ & -- & --- \\
\hline Cholesystectomy & 2 & 0 & 3-Feb & $\begin{array}{l}\text { Less than open } \\
\text { surgery }\end{array}$ & --- & ---- \\
\hline $\begin{array}{l}\text { Diagnostic } \\
\text { Laparoscopic }\end{array}$ & 7 & 0 & $0-1$ & $\begin{array}{l}\text { Less than open } \\
\text { surgery }\end{array}$ & --- & --- \\
\hline Orchidopexy & 3 & 0 & $0-1$ & $\begin{array}{l}\text { Less than open } \\
\text { surgery }\end{array}$ & ---- & $\begin{array}{l}\text { I keloids } \\
\text { performed }\end{array}$ \\
\hline
\end{tabular}

\section{Discussion}

Single-port surgery has left its mark in minimal access surgery and has been adopted by some centres with very good results for all kinds of intra abdominal surgeries. All the initial studies show it to be feasible, reasonably safe and cosmetically advantageous to standard laparoscopy. ${ }^{1}$

Because there is only one incision, typically in the umbilicus, the distance in the umbilicus to the surgical field might be longer than with the conventional laparoscopic technique ${ }^{2-4}$ (Figure 3-11).

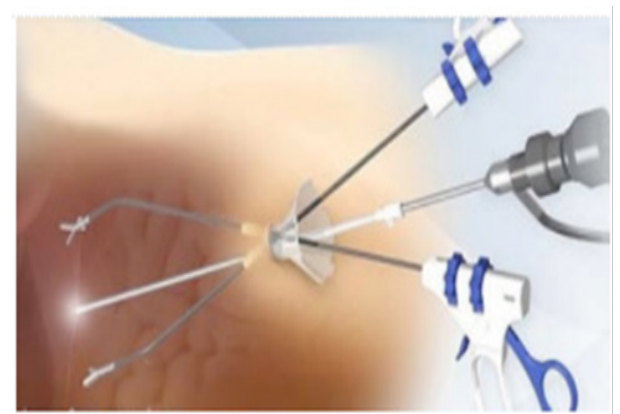

Figure 3 Pediatric laparoscopy.

Indications of laparoscopic surgeries in children

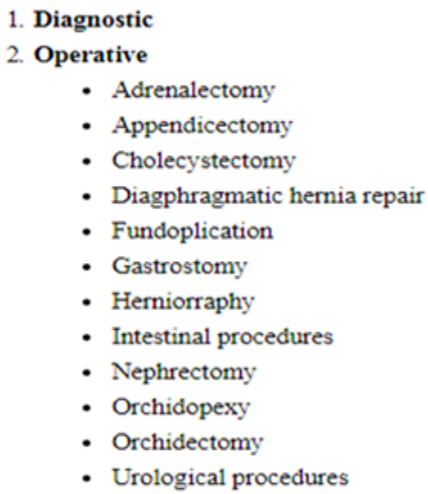

Figure 4 Indications of laparoscopic surgeries in children.

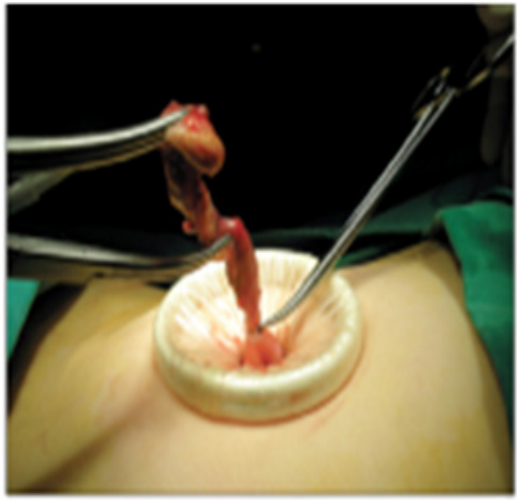

Figure 5 Single Incision Laparoscopic Surgery for Acute Appendicitis.
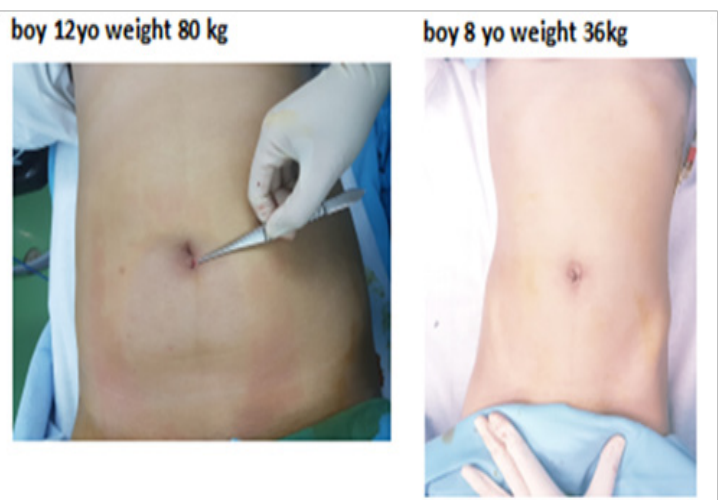

Figure 6 One hole laparoscopy appendectomy.

During the past two decades the indications of pediatric laparoscopy have been expanded from diagnostic use and simple operations to complex hepatobiliary and urological reconstructive surgery. All the initial studies show it to be feasible, reasonably safe and cosmetically advantageous to standard laparoscopy. Obviously one would not see a stark benefit as one did between open surgery and laparoscopy when it first began. It will no doubt be spurred on by rapid advances in technology and better instrumentation that is likely to follow. Experienced laparoscopic skills are obviously needed to accomplish safe single-port surgery. Diagnostic laparoscopy of 
children was started in 1970s for evaluation of non-palpable testes and patency of contralateral hernial sac. With refined instruments and techniques, it is now possible to evaluate the contralateral hernial sac through the ipsilateral hernia sac with the use of a $3 \mathrm{~mm}$ angled scope. Moreover diagnostic laparoscopy is being increasingly used for evaluation of abdominal pain, tumor staging, diagnostic biopsy and evaluation of penetrating abdominal trauma in children. The only truth in surgery is change. Reducing scars and the insult of surgical trauma has become a vital end point of all surgical assessment and endeavour. ${ }^{2-5}$

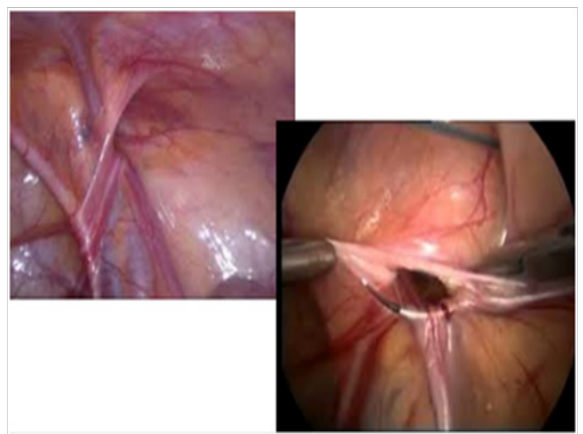

Figure 7A Laparoscopic surgery for inguinal hernia in children.

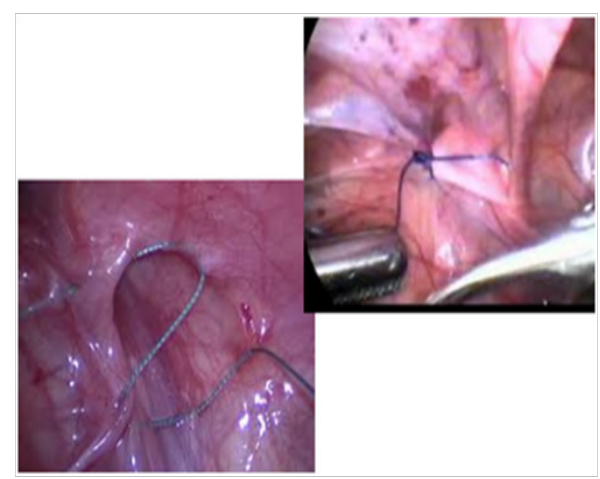

Figure 7B Laparoscopic surgery for inguinal hernia in children.

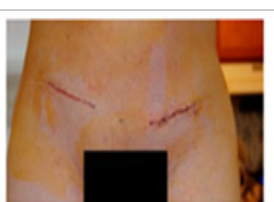

Open

Procedure

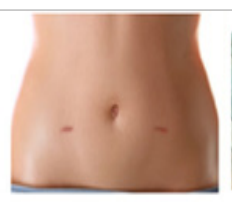

Traditional Laparoscopic Procedure

Figure 8 Post Operation scars heriotomy.
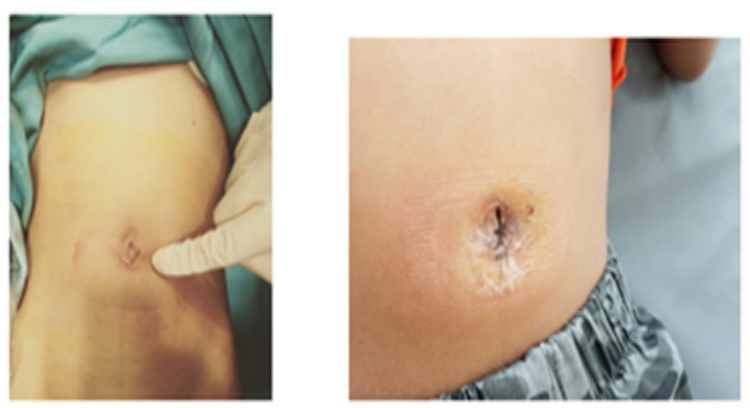

Figure 9 Single incision laparoscopic of hernia inguinal surgery.

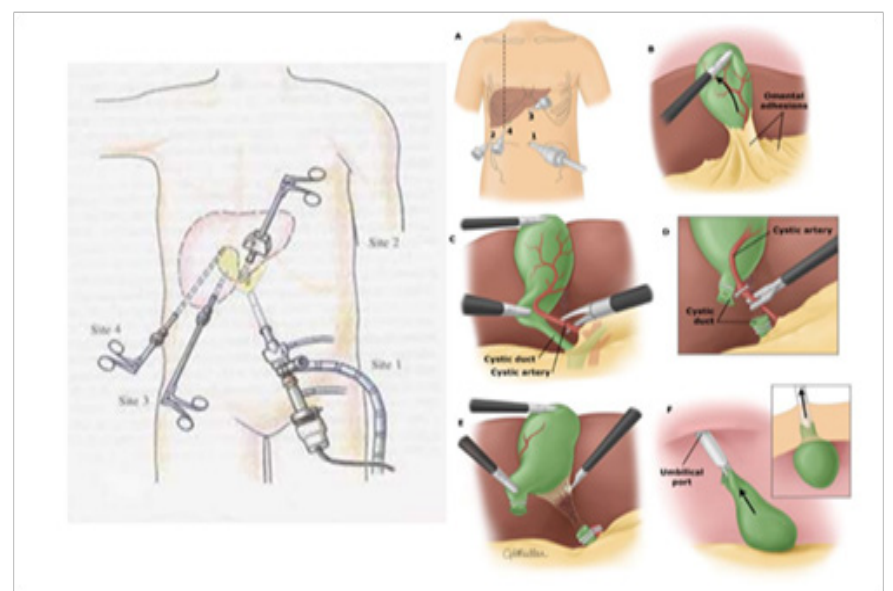

Figure 10 Laparoscopic surgery for cholecystectomy in children.
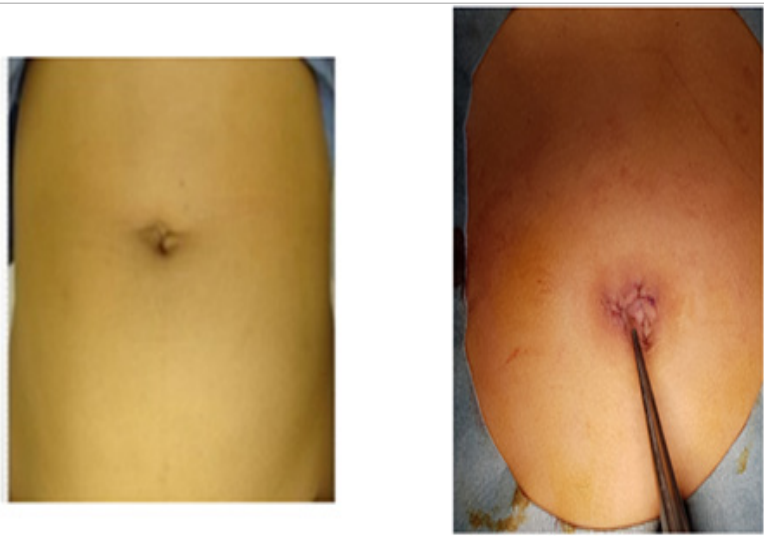

Figure II Single incision laparoscopic cholecystectomy surgery.

The cost factor, given the access devices and other instrumentation, is significantly more as are the learning curve and operative times. Of course, the cost would be negated if one used the SIMPLE technique and standard laparoscopic instruments, but the other problems remain. ${ }^{5,7-11}$ This has been aptly described as SIMPLE by some authors. The transumbilical technique for cholecystectomy, without additional incisions, was described first by Navarre et al. in 1997 and later Piskun et al. in 1999 (Figure 12).

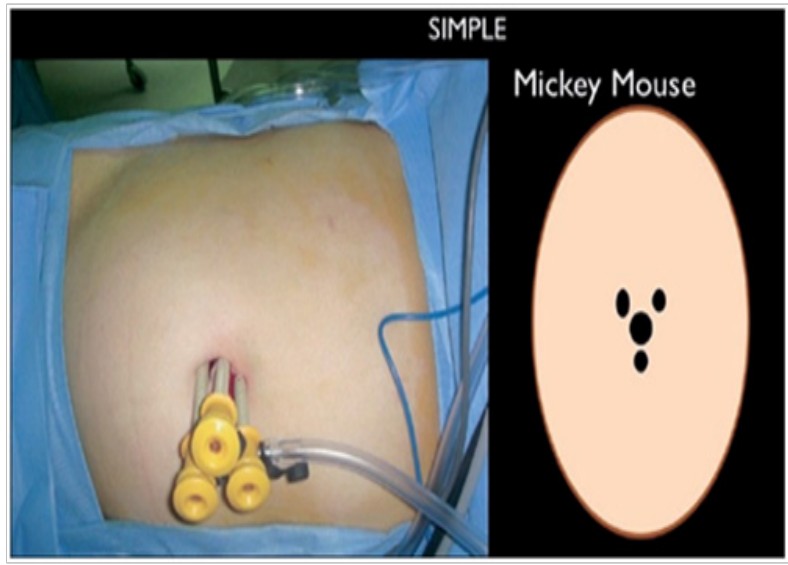

Figure I2A 

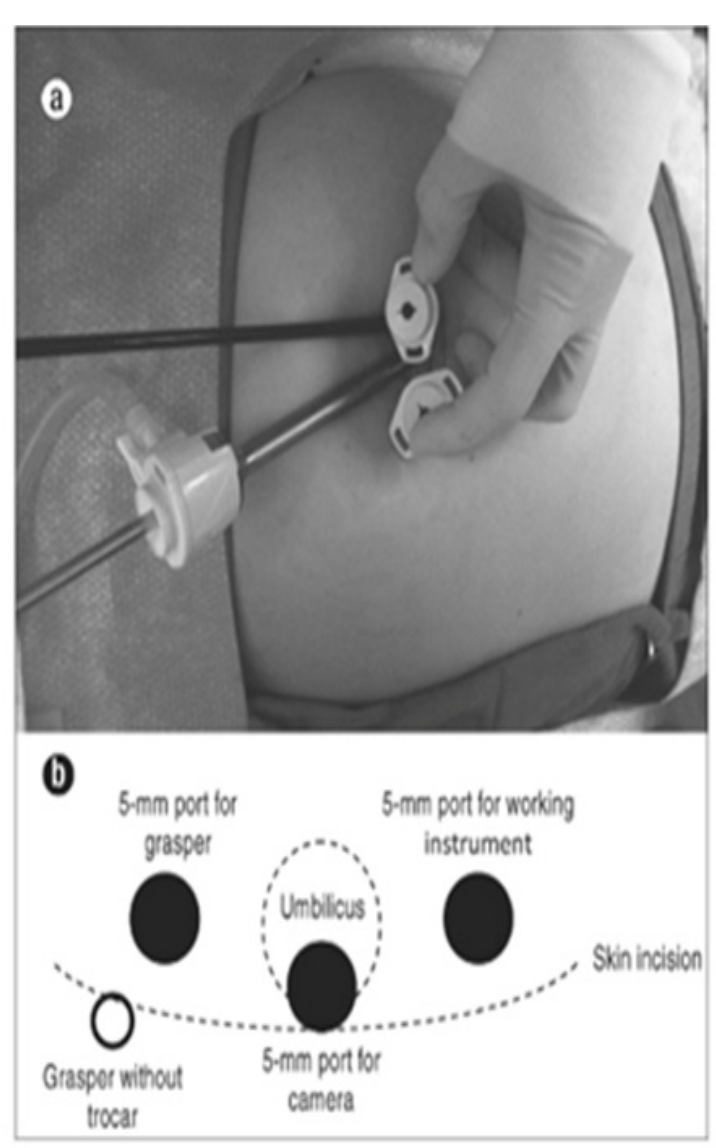

Figure I 2B The transumbilical technique for cholecystectomy.

\section{Conclusion}

Single-port surgery has left its mark in minimal access surgery and has been adopted by some centres with very good results for all kinds of intra abdominal surgeries. The single incision laparoscopic surgery (SILS) approach offer advantages others than fine cosmetic result as no incisions, children comforts, potentially reduces the surgical stress and fluid shifts that may accompany it, decreased of infection, in addition there is less need for postoperative analgesia, reduction of postoperative respiratory and wound complications; shortens postoperative convalescence, including an intensive care unit stay; rapid return to normal diet and decreased overall hospital stay and better clinical information.

\section{Acknowledgements}

None.

\section{Conflict of interest}

The author declares no conflict of interest.

\section{References}

1. Rattner D, Kalloo A. ASGE/SAGES working group on natural orifice translumenal endoscopic surgery. October 2005. Surg Endosc. 2006;20(2):329-333.

2. Zornig C, Mofid H, Siemssen L, et al. Transvaginal NOTES hybrid cholecystectomy: Feasibility results in 68 cases with mid-term follow-up. Endoscopy. 2009;41(5):391-394.

3. Box GN, Lee HJ, Santos RJ, et al. Rapid communication: Robot-assisted NOTES nephrectomy: Initial report. J Endourol. 2008;122(3):503-506.

4. Rao PP, Rao PP, Bhagwat S. Single-incision laparoscopic surgery - current status and controversies. J Minim Access Surg. 2011;7(1):6-16.

5. Haber GP, Crouzet S, Kamoi K, et al. Robotic NOTES (Natural Orifice Translumenal Endoscopic Surgery) in reconstructive urology:Initial laboratory experience. Urology. 2008;71(6):996-1000.

6. Gill IS, Advincula AP, Aron M, et al. Consensus statement of the consortium for laparoendoscopic single-site surgery. Surg Endosc. 2010;24(4):762-768.

7. Junker H. [Laparoscopic tubal ligation by the single puncture technique (author's transl)]. Geburtshilfe Frauenheilkd. 1974;34(11):952-955.

8. Bailer P, Rauskolb R. [Gynaecological laparoscopy (author's transl)]. Geburtshilfe Frauenheilkd. 1975;35(10):747-753.

9. Palanivelu C, Rajan PS, Rangarajan M, et al. (Transumbilical endoscopic appendectomy in humans: On the road to NOTES: A prospective study. J Laparoendosc Adv Surg Tech A. 2008;18(4):579-582.

10. Raman JD, Bensalah K, Bagrodia A, et al. Laboratory and clinical development of single keyhole umbilical nephrectomy. Urology. 2007;70:1039-1042.

11. Raman JD, Cadeddu JA, Rao P, et al. Single-incision laparoscopic surgery: Initial urological experience and comparison with natural-orifice transluminal endoscopic surgery. BJU Int. 2008;101(12):1493-1496. 